\title{
LOS SIETE ASPECTOS FUNDAMENTALES PARA LA EDUCACIÓN DEL SIGLO XXI SEGÚN EDGAR MORIN. UNA MIRADA DESDE LA COMPLEJIDAD Y LA TEORÍA DE SISTEMAS
}

\author{
THE SEVEN FUNDAMENTAL EDUCATION ASPECTS FOR EDUCATION IN THE 21st \\ CENTURY ACCORDING TO EDGAR MORIN. \\ A LOOK FROM COMPLEXITY AND SISTEM THEORY
}

\author{
Rodrigo Meza Aliaga \\ Sociólogo \\ Magister en Educación \\ Municipalidad de Recoleta, Santiago, Chile \\ rodimeza@gmail.com
}

\begin{abstract}
Resumen: El último cambio de siglo ha traído aparejado profundas modificaciones en las diferentes esferas de la vida humana, la educación como una de las más importantes no escapa a ello. El presente artículo pretende precisamente mostrar, a través de los planteamientos de Edgar Morin y otros autores provenientes de diferentes disciplinas y teorías, la ineficacia de continuar educando en el siglo XXI de la misma forma en que se hacía en el siglo XX y anteriores. El texto inicia realizando una distinción entre educación y pedagogía, para luego avanzar en la exposición de los aspectos que Morin señala como pilares fundamentales al momento de enfrentar la educación en la nueva centuria. Desde un principio la idea del relato es intentar apoyar y hacer conversar los planteamientos del teórico francés con los de otros autores cuyas ideas, de una u otra forma permiten complementar, aclarar y profundizar algunos aspectos presentes en las ideas morinianas.
\end{abstract}

Palabras clave: complejidad, teoría de sistemas, sinergia, conocimiento pertinente, unidad en la multiplicidad.

Abstract: The last turn of the century has brought about profound changes in the different spheres of human life, education as one of the most important does not escape this. This article aims precisely to show, through the approaches of Edgar Morin and other authors from different disciplines and theories, the ineffectiveness of continuing to educate in the 21st century in the same way as in the 20th century and earlier. The text begins by making a distinction between education and pedagogy, and then advances in the exposition of the aspects that Morin points out as fundamental pillars when facing education in the new century. From the beginning, the 
idea of the story is to try to support and converse the approaches of the French theorist with those of other authors whose ideas, in one way or another, allow to complement, clarify and deepen some aspects present in Morinian ideas.

Keywords: complexity, systems theory, synergy, relevant knowledge, unity in multiplicity.

\author{
"La educación no es \\ preparación para la vida, \\ la educación es \\ la vida en sí misma". \\ John Dewey
}

\title{
INTRODUCCIÓN
}

El año 1999 la UNESCO publica el texto Los Siete Saberes Necesarios Para la Educación del Futuro, el cual había sido encargado al filósofo y sociólogo francés Edgar Morin. En él, el autor se refiere a una serie de elementos centrados en siete pilares conceptuales que considera indispensables para la educación ${ }^{1}$ en el siglo XXI.

El eje teórico que cruza transversalmente este texto es el Pensamiento Complejo de Edgar Morin en relación a los requerimientos de la educación para el nuevo siglo, y cómo este y otros planteamientos, pueden ser un aporte para lograr que la educación y la pedagogía no sigan trabajando en esta nueva centuria, ni con las estrategias ni con los paradigmas, las técnicas, los intereses ni los errores que le fueron concomitantes el milenio pasado.

En el presente trabajo, las ideas de Morin serán apoyadas y reforzadas con aportes de otros autores Tales como Alberto Montbrun o Niklas Luhmann, entre otros, quienes, con mayor o menor cercanía a sus planteamientos, aperturan, extienden y amplían las ideas morinianas (el primero desde el Paradigma de la Complejidad propiamente tal y el segundo desde la teoría de sistemas, con gran uso de elementos semánticos de la Complejidad).

Los siete saberes a los que alude el autor quedan plasmados en los capítulos del texto:

- Las cegueras del conocimiento: el error y la ilusión

- Los principios de un conocimiento pertinente

- Enseñar la condición humana

- Enseñar la identidad terrenal

- Enfrentar las incertidumbres

- Enseñar la comprensión

- La ética del género humano

Cada uno de los capítulos va detallando a manera de diagnóstico, la forma de entender la educación en el siglo pasado, así como la epistemología y la propuesta de una nueva forma de 
implementar la educación y la pedagogía en este nuevo escenario, bajo nuevas exigencias y problemáticas (al decir del propio Morin, problemáticas y peligros reales que hoy afectan a todo el orbe). Todo ello permeado como ya se ha indicado, por la nueva configuración y mirada que nos permite el desarrollo de un paradigma de la complejidad.

\section{ANTECEDENTES TEÓRICOS}

Antes de continuar, se debe aclarar la distinción ya señalada entre educación y pedagogía, conceptos que, desde el sentido común, pueden parecer sinónimos. Educación proviene del latín, y su última palabra trazable es "educare", formado por el prefijo "ex" (fuera) y el verbo "ducere" (guiar, conducir). Educare a su vez proviene de "educere" (sacar, extraer). Pedagogía por su parte proviene del griego "paidos" (niño) y "agen" (conducir), por extensión, se entiende como el que guía a un niño. Desde la doxa, la distinción entre ambos conceptos no es relevante, pero para las pretensiones de este trabajo sí. La idea es que Educación es un concepto más abstracto y general que el de pedagogía. Para la sociología, por ejemplo, es un tipo de estructura social. Ya Durkheim en 1922 aludía a esta desde una perspectiva bastante abstracta, para luego ir identificándola cada vez más con el proceso de socialización: "Para que haya educación, es necesaria la presencia de una generación de adultos y una generación de jóvenes, así como de una acción ejercida por los primeros sobre los segundos." (Durkheim, E. 2003 p. 59).

A diferencia de la educación, la pedagogía adquiere, sobre todo a fines del siglo XX y en lo que va de siglo XXI, un carácter mucho más pragmático, es la propia educación la que ha hecho de la pedagogía una especie de tecnología social que permite procedimentar los aprendizajes.

De esta forma, la Educación en tanto que hecho social, externo al ser humano y coercitivo sobre su accionar (Durkheim 1895), puede ser organizada tecnológicamente de distintas formas. Puede ser la pedagogía, o el concepto de educación popular u otra variante que se oriente al aprendizaje procedimental.

La idea final acá y la base de esta distinción es señalar que cuando Morin habla de educación, está apuntando en realidad a lo que hoy en el siglo XXI es la pedagogía, al rol que esta debe cumplir en esta nueva etapa. ${ }^{2}$

La pedagogía en este nuevo siglo debe necesariamente incorporar una serie de competencias que no se requerían antiguamente. Carbonell explica muy bien esto: "Ahora, sin embargo, el cambio más novedoso y sustancial es que la cantidad de información, conocimientos, dispositivos y oportunidades formativas se multiplican fuera de la institución escolar. Y lo que aún es más importante: todo ello no se limita a la difusión controlada y jerarquizada de antaño, sino que se abre y democratiza el acceso para la comunicación, el intercambio, la construcción e intervención en torno a la información y el conocimiento. Eso cuestiona aún más el lugar de la escuela en la trasmisión del saber y en el proceso de enseñanza y aprendizaje". (Carbonell, J. 2015 p. 28). 
De esta forma, si la pedagogía tiene que ver con el guiar al paidos (niño), con conducirlo adecuadamente para su inserción en la sociedad, este rol hoy está mucho más difuminado. La vieja distinción socialización primaria / socialización secundaria (Berger y Luckmann 1986) traducida en el binomio familia / escuela, hoy se ve complejizada por la existencia de múltiples agentes socializadores, entre los cuales los medios de comunicación y las TICs aparecen como los más destacados.

Los planteamientos de Morin apuntan, además de una manera de entender al mundo desde la complejidad, a una forma de desarrollar la pedagogía incorporando aspectos sistémicos, sociohistóricos, éticos, políticos, contextuales, tecnológicos acordes al siglo XXI. Como complemento de esto también se puede hacer alusión a la introducción de aspectos tales como el pensamiento crítico y la creatividad. ${ }^{3}$

Complejidad:

La Complejidad es un término amplio y polisémico cuya semántica ha ido variando conforme se ha afianzado el denominado "Paradigma de la Complejidad".

Hay quienes plantean que serían teóricos de la complejidad todos aquellos que realizan estudios desde la teoría de sistemas (Castro 2011), ubicando acá un arco sumamente amplio que iría desde los primeros aportes de Bertalanffy en la década del 50', hasta visiones más contemporáneas como las del citado Montbrun, Gregory Bateson, Maturana, Marcelo Arnold, Niklas Luhmann, Darío Rodríguez y un largo etcétera.

Efectivamente las ideas de Morin incluyen muchos elementos de la semántica sistémica, pero este autor impone un sello diferente al análisis de la complejidad. Realiza una mirada desde el mundo humanista, menos pragmática que, contemporáneos suyos como Luhmann.

La complejidad en Morin tiene que ver con un mundo cada vez más diverso, donde la división del trabajo y la híper especialización han provocado cambios importantes tales como la profundización del proceso de globalización iniciado hacia la segunda mitad del siglo XX, o la masificación del uso de internet, haciendo de esta forma que un proyecto militar iniciado en los 60 en EEUU (arpanet), hoy esté instalado en los hogares del planeta, generando una serie de cambios en la forma de relacionarse (redes sociales), de consumir, de informarse, de realizar transacciones comerciales, de estudiar, etc. Es esa multidiversidad la que hace que el mundo sea hoy más complejo que nunca, y por ende más difícil de explicar que en cualquier otro período histórico.

Ante este dilema, las explicaciones y comprensiones están orientadas a ver la parte y no el todo, a intentar explicar el todo a partir de una parte, careciendo completamente de una visión de contexto que indique que aquello por lo cual se está partiendo para explicar (la parte), no es más que un componente de una maquinaria más grande, de un contexto más amplio y complejo.

El llamado de Morin es a pensar contextualmente la singularidad, a ser capaces de ver lo múltiple en lo singular, ver a este último como parte de un contexto general más amplio. 
En la terminología sistémica luhmanianna, la complejidad tiene primero que ver con una dinámica de diferenciación. Todo sistema tiene la calidad de tal precisamente porque ha realizado una labor de diferenciación de su entorno. "Se puede decir que el sistema es su diferencia respecto al entorno." (Arnold, M y Rodríguez, D. 1990 p. 102). En palabras de estos dos autores", la complejidad para Luhmann implica que "Si se tiene un sistema con un número creciente de elementos, se hace cada vez más difícil relacionar cada elemento con cada uno de los demás. La complejidad requiere selección." (op. cit.). Esta selección tiene que ver en parte con el proceso de diferenciación que realiza el sistema respecto del entorno. En su labor diferenciadora, el sistema distingue y elije qué tomará y qué no tomará del entorno. Los sistemas están obligados a ello, pues requieren constantemente reducir complejidad "La selección es el elemento central y vital en la reducción de la complejidad." (Castro, B. 2011 p. 287).

Finalmente, respecto de la complejidad desde la perspectiva luhmanianna, "Resumiendo, la complejidad es un concepto que relaciona sistema y mundo, todo sistema surge en una operación de distinción respecto de un entorno. Sistema y entorno aparecen en la misma operación de distinción. El sistema se constituye en su diferenciación del entorno." (Arnold, M y Rodríguez, D. 1999 p. 102).

A modo de síntesis de esta última parte, la complejidad moriniana implica un mundo diverso en donde parte del error radica en la imposibilidad humana de explicar y comprender el mundo globalmente, a falta de lo cual se elaboran respuestas y comprensiones locales, singulares, particulares, desligadas totalmente del contexto mayor en el cual deben ser analizadas. Luhmann por su parte ve a los sistemas ( $y$ a la sociedad entre ellos) como el resultado de procesos continuos de diferenciación respecto de un entorno más amplio. Acá la complejidad es tematizada como el producto del crecimiento del sistema, a raíz de lo cual, los componentes del mismo (que a su vez son subsistemas), ya no tienen posibilidad de tener conexión o relación de cada elemento con cada uno de los restantes componentes del sistema (Arnold y Rodríguez 1999).

En ambas concepciones, la complejidad tiene que ver con una multiplicidad de elementos componentes de un todo. En el caso de Morin la complejidad se resuelve teniendo una visión de conjunto, una mirada global-contextual de los fenómenos, a partir de la cual realizar las explicaciones y la comprensión de un mundo complejo, lo que permitirá a su vez, tomar decisiones basadas en criterios holísticos. En Luhmann el tratamiento de la complejidad está dado por la capacidad de los sistemas de reducir complejidad, "reducción de la complejidad a través de la construcción de un sistema que, reduzca el problema a una cuestión de selección. Este enfoque posterior es el de la teoría cibernética ${ }^{5}$ de sistema" (Castro, B. 2011 p. 287).

Para finalizar esta parte, se debe señalar que, tanto en los planteamientos de Morin como de Luhmann, no es posible explicar el todo desde la parte. En el primer autor por un tema de contextualidad (no se puede entender lo global a partir de lo local) y en el segundo por la sinergia, concepto que da cuenta de un todo complejo que debe su existencia al trabajo mancomunado de cada uno de los componentes del sistema, labor en la cual la cohesión es tal, que es muy difícil separar o afectar a una parte, sin afectar el funcionamiento completo del sistema. 


\section{ANÁLISIS}

\section{1.- Las cegueras del conocimiento: el error y la ilusión}

El autor inicia este capítulo cuestionando la idea de que podamos tener conocimiento cabal y certero de la realidad (eso que está allá afuera...), pues lo que llamamos conocimiento, no es un reflejo fiel del mundo exterior, sino una traducción y reconstrucción realizada por nuestra mente (cerebro) a partir de estímulos que afectan nuestros sentidos ${ }^{6}$. Se apoya para este mismo ejemplo en lo planteado por Marx y Engels en la Ideología Alemana (1846), donde los autores deslizan la idea de que la humanidad siempre ha desarrollado falsas concepciones sobre ellos mismos.

En concreto, Morin plantea que este conocimiento, transportado por la palabra y traducido/reconstruido por la mediación del lenguaje y el pensamiento, a lo menos debe concedérsele el riesgo o la posibilidad de subjetivo... Morin (1999) también advierte del riesgo de error e ilusión en el conocimiento inducido desde las emociones incluyendo en ello a la "afectividad", la que, al decir del autor, si bien puede anular el conocimiento, también puede fortalecerlo ${ }^{7}$, generando con ello una paradoja ${ }^{8}$ propia del paradigma de la complejidad.

En el texto se advierte que los mismos "paradigmas que controlan la ciencia pueden desarrollar ilusiones y ninguna teoría científica está inmunizada contra el error" (Morin, E. 1999 p. 6).

He aquí una de las primeras recomendaciones del autor para la educación (más bien pedagogía si pensamos en la distinción anteriormente realizada) de este nuevo siglo: identificar el origen de las ilusiones y los errores.

Señala como fuente de error también al egocentrismo, sobre todo a cierto nivel de creación científica, en donde la posibilidad de reconocer un error (sea a nivel de personas o disciplinar) es más escasa. Tanto teóricos como teorías se hacen, según el texto, resistentes a los embates de otras perspectivas y visiones.

Nos advierte también Morin del peligro que conlleva la razón en tanto que racionalidad, y el peligro de que esta última se transforme en racionalización, entendiendo por aquello, que, desde las mismas fuentes de la racionalidad, la racionalización constituya errores e ilusiones más poderosas. Esto principalmente por la falta de crítica y autocrítica en su mecánica de funcionamiento. ${ }^{9}$ En este mundo complejo, híper especializado, donde ya no es posible realizar conexiones unívocas entre todos los componentes de los sistemas (sociales en este caso), la educación y la pedagogía del futuro deben contemplar el principio de la incertidumbre, la racionalidad debe ser ante todo crítica y autocrítica.

El autor identifica otra fuente de error e ilusión a nivel del (los) paradigma (as) imperante (s), señalando que hoy bajo la égida del paradigma cartesiano (positivista, racionalista, mecanicista) el mundo tiende a polarizarse o dicotomizarse en posiciones extremas (sujeto/objeto, alma/cuerpo, calidad/cantidad, etc.), lo que impediría tener un panorama de contexto que permita una visión integral de las problemáticas. A ello también se debe adicionar 
la potencia de un paradigma en orden a hacernos ver, creer y pensar lo que el paradigma establece ${ }^{10}$.

Uno de los grandes problemas de los sistemas de pensamiento llamados paradigmas, es que estos se cierran a nuevas ideas ${ }^{11}$. "Necesitamos un control permanente para evitar el ideologismo y racionalización” (op. cit. p. 13). En síntesis, hoy más que nunca se requiere de un paradigma complejo.

\section{2.- Los principios de un conocimiento pertinente}

En el capítulo I del texto ya se introduce la idea de la fragmentación del conocimiento, así como las consecuencias de aquello. Es gracias a esta mecánica, que no podemos percibir los problemas sistémicos que el mundo presenta hoy. Hay acá un llamado no a olvidar lo local (la parte), sino a abordar que está dentro de lo global (el todo), con una perspectiva de contexto, integradora. La idea es no analizar la parte por separado, sino con la conciencia de que esta pertenece a un todo funcionando... acercarse a lo local desde una mirada sinérgica que me indica que aquello que estoy analizando, es parte de una entidad más amplia y compleja.

Vuelve a surgir acá la necesidad de un cambio de paradigma que permita superar estos aspectos: "La era planetaria necesita situar todo en el contexto de la complejidad planetaria." (op. cit. p. 15).

La pregunta es ¿cómo en un mundo tan diverso como el actual, podemos percibir lo global, lo múltiple, lo complejo?... Morin asigna precisamente esa tarea a la educación del siglo XXI, unir nuestros saberes para comprender realidades multidimensionales de orden planetario.

Bajo tales exigencias... qué debe hacer la educación trasuntada en pedagogía... Primero, debe evidenciar el contexto, o lo que es lo mismo, situar tanto la información circulante como el conocimiento en contextos más amplios que permitan que emerja un sentido diferente, que esté más allá de lo meramente local. El conocimiento debe enfrentar lo complejo: "hay complejidad cuando son inseparables los elementos diferentes que constituyen un todo." (op. cit. p. 17). Morin entiende la complejidad como una síntesis entre lo local y lo global, entre la unidad y lo múltiple.

El texto plantea la existencia de una inteligencia general, esta permite analizar con una visión de conjunto los casos particularidades, analizar lo local con una perspectiva múltiple. Es precisamente este tipo de inteligencia la que debe impulsar la Educación del siglo XXI, en la medida que se hace esto, se contribuye a despertar la curiosidad eclipsada por la instrucción clásica.

El llamado es a volver a pensar en el todo como el telón de fondo del desarrollo sociohistórico, sólo con esta visión holística podremos analizar lo local y sus particularidades, "hay presencia del todo al interior de las partes"12 (op. cit. p. 17). Toda esta fragmentación de la dimensión humana (lo biológico separado de lo social, lo social de lo cultural, lo religioso, etc.) genera la pérdida del sentido de contexto y de la posibilidad de encajar los saberes individuales en un conjunto más amplio, repercute en un debilitamiento de la solidaridad. A partir de ello comenzamos a ser seres atomizados en sociedades igualmente atomizadas. 
Un paradigma de la complejidad requiere sortear las vayas impuestas por la hiperespecialización, volviendo la mirada a lo global, ser cautelosos con la abstracción, pues esta saca los objetos de su contexto, descontextualiza...

Todo ello nos invita a desconfiar del principio de reducción, ya que "nuestra educación nos ha enseñado a separar, compartimentar, aislar y no a ligar los conocimientos." (op. cit. p. 19).

Tal compartimentalización del conocimiento del contexto lleva a que los grandes problemas de la humanidad (ecológicos, amenaza nuclear, epidemias, alimentarios, racismo, económicos, recursos naturales, etc.) se diluyan en la fragmentación. Morin (1999) habla de una inteligencia miope, incapaz de comprensión global, tildándola de falsa racionalidad.

\section{3.- Enseñar la condición humana}

El capítulo inicia mostrando cómo, hace (quizá) unos 15 mil millones de años se habría formado el cosmos. Señala también que las partículas que forman nuestros organismos aparecieron en los primeros segundos de nuestro universo, somos entonces polvo de estrellas. Morin pone de relieve la autoorganización de la vida, misma de la cual somos una especie de producto final (si es que este proceso tuviese un final). En tales circunstancias, el autor afirma que la tierra "se auto-produjo y auto-organizó dependiendo del sol", "Somos a la vez seres cósmicos y seres terrestres" (Morin, E. 1999 p. 23).

Plantea la idea de la "condición humana". Esta incorpora aspectos de animalidad y humanidad, refiriéndose a factores tales como la hominización, la que conlleva al desarrollo del lenguaje y de la cultura. Respecto de la hominización, esta además implica "bipedización, manualización, erección del cuerpo, cerebralización, juvenilización”. (op. cit. p. 24). Respecto del lenguaje y la cultura, se liga a éstos la adquisición de saberes, creencias, mitos. El homínido se humaniza.

Señalar sobre la humanización y a la culturización que ambas nos alejan de lo físico y lo cósmico que somos, un "cosmos que nos es secretamente íntimo" (op.cit). He aquí otra vez el llamado de Morin a entender nuestra multidimensionalidad.

Es la cultura la que nos diferencia de los primates. A partir de esta idea, el autor desarrolla la tríada cerebro - mente - cultura, estos tres conceptos se afectan y producen mutuamente, de manera dialéctica ${ }^{13}$.

El autor también nos plantea la tríada razón - afecto - impulso, señalando que la racionalidad es por constitución cerebral, pero esta depende y se relaciona con la afectividad y la impulsividad.

Otra tríada sugerida por Morin es: individuo - sociedad - especie, donde también se plantea una relación sistémico-dialéctica. La complejidad humana está dada por la afectación sinérgica de estos tres componentes.

La educación, plantea este autor (y nosotros agregamos a la pedagogía) "deberá velar porque la idea de unidad de la especie humana no borre la de su diversidad, y que la de su 
diversidad no borre la de la unidad". (op. cit. p. 26). La educación que se viene deberá educar en una unidad diversa. La comprensión de lo humano es la comprensión de la unidad en la multiplicidad.

El autor prefiere hablar de culturas en plural, pues acá se implica la pluralidad y la diversidad cultural de los seres humanos. Las culturas son unidad y diversidad, son costumbres, tradiciones, mitos, saberes, técnicas, sistemas de pensamiento. Parecen cerradas para salvaguardar su identidad, pero también son apertura "integran en ellas no solamente saberes y técnicas sino también ideas, costumbres, alimentos ${ }^{14}$, individuos provenientes de otras partes". (op. cit. p. 28). La antropología tiene definiciones amplias para este tipo de fenómeno, por ejemplo, la transculturación.

En este nuevo período, deberá abandonarse esa visión estática del ser humano, puramente racional, pues también somos seres de afectividad, de mitos, de bailes, creencias, embrujos, sanaciones, etc. ${ }^{15}$ El ser humano es más que racionalidad y técnica, incluso se prepara para la vida más allá de la muerte.

Hay una invitación en Morin a ver al ser humano en la filigrana de la modernidad, tras lo cual seguimos llevando algo de soñador, de bromista, de amante, de enamorado, de loco. "El genio surge en la brecha de lo incontrolable, justo ahí donde merodea la locura". (op. cit. p. 30). La educación y la pedagogía del Siglo XXI deberán indagar en la complejidad, tomar conciencia de lo individual en la multiplicidad y viceversa

\section{4.- Enseñar la identidad}

Morin abre este capítulo invitando a pensar los problemas del siglo XXI por medio de la comprensión de la condición humana en el mundo, esto es, con una conciencia planetaria. Entendiendo por esta última a la era de la humanidad en la que el desarrollo técnico-económicocientífico cada vez homogeniza más los problemas de la especie. "El problema planetario es un todo que se alimenta de ingredientes múltiples, conflictivos, de crisis; los engloba, los aventaja y de regreso los alimenta." ${ }^{16}$ (op. cit. p. 32).

Señala el autor que el problema que tenemos para conocer el mundo es nuestro pensamiento atrofiado. Carecemos cada vez más de la capacidad de contextualizar y globalizar (Morin. 1999). "la exigencia de la era planetaria es pensar la globalidad, la relación todo-partes, su multiplicidad, su complejidad." (op. cit.). Esto implica considerar la diversidad más que la unidad... arribar al pensamiento complejo. Tal manera de pensar implica ver a la sociedad como un macrosistema, compuesto de subsistemas, carente de un centro o eje ordenador.

Las sociedades modernas constituidas sistémicamente no tienen, ni pueden tener este eje ordenador central (Luhmann. 1997), pues al estar un sistema altamente complejo como la sociedad compuesto por subsistemas a su vez autopoieticos y sinérgicos, donde cada uno de estos es capaz de realizar un trabajo de retroalimentación y cibernética (black box), la labor ordenadora recae en cada subsistema ${ }^{17}$. 
En este nuevo siglo, necesitamos un sistema de pensamiento policéntrico que apunte al universalismo. De este modo, requerimos una educación y una pedagogía que apunten a la conciencia planetaria.

La planetarización en el siglo XX ha generado una economía globalizada, una humanidad que se vuelve cada vez más un todo interdependiente, donde cada vez más se tiende a lo que Marshall Mcluhan en los 70' llamó “Aldea Global”, un mundo altamente interconectado e interdependiente en todo orden de cosas (económico, tecnológico, productivo, cultural, comunicacional, etc.).

Hace notar Morin que este proceso de planetarización inicia en el occidente europeo con los grandes viajes de descubrimiento. Es por ello que el europeo hoy es uno de los más beneficiados con el proceso "Mientras el europeo se encuentra en este circuito planetario de confort, un gran número de Africanos, Asiáticos, Suramericanos se encuentran en un circuito planetario de miseria." (op. cit. p. 34).

Este último planteamiento de Morin tiene un correlato en lo señalado desde los 60' en adelante en Latinoamérica por autores tales como Fernando Henrique Cardozo, Enzo Faletto, Theotonio Dos Santos, en lo que se conoce como Teoría de la Dependencia. Corriente de pensamiento que, a grandes rasgos y de manera teórica, dividía el mundo en países centro y países periféricos (metrópoli - satélite), esto para explicar el funcionamiento de la economía mundial y en particular el rol asignado a los países que no han alcanzado el desarrollo: producir materia primas.

Sin ser necesariamente un posmoderno, Morin plantea que, si por modernidad se entiende a esa vorágine que destruye el planeta, que extrae irracionalmente recursos naturales, deteriorando a la larga la calidad de vida de la humanidad, esa modernidad ha muerto.

El texto continúa mostrando cómo a finales del siglo pasado se habría empezado a gestar todo un bloque de movimientos críticos que el autor define como contracorrientes. Con este concepto designa a una serie de saberes en diferentes ámbitos del conocimiento y de la esfera social que han sido capaces de construir una mirada crítica respecto del establishment. Estas contracorrientes críticas serían:

- La contracorriente ecológica

- La contracorriente cualitativa

- La de resistencia a la vida prosaica

- La de resistencia a la primacía del consumo

- La de emancipación respecto de la tiranía de la omnipresencia del dinero

- La de reacción a la violencia

La primera prácticamente se explica per se, alude a toda la crítica a la destrucción del planeta (más bien de la especie) a partir del daño a la ecología planetaria. La segunda se orienta a criticar la hegemonía del cuantitativismo y a su visión uniformizadora (aun cuando no hay un desarrollo extenso del concepto, la crítica pareciera dirigirse al positivismo). La tercera contracorriente alude a lo vacuo de una vida consagrada a lo material, oponiendo a ello "la búsqueda de una vida 
poética, dedicada al amor, a la admiración, la pasión, el festejo." (op. cit. p. 37). La cuarta contracorriente realiza críticas al consumo exacerbado que se aprecia en las sociedades modernas. Las dos últimas contracorrientes según Morin están en un período de emergencia, iniciándose. La contracorriente de emancipación ante el dinero se hace cuerpo en la idea de solidaridad ${ }^{18}$, en tanto que la última plantea una ética de la pacificación.

A partir de estas contracorrientes y de otros movimientos culturales e intelectuales, es que se avizora y pone en el tapete de la discusión, la necesidad de cambiar el decimonónico paradigma mecanicista/positivista por otro capaz de comprender globalmente los problemas que nos afectan como humanidad: "Una de las condiciones fundamentales para una evolución positiva sería que las fuerzas emancipadoras inherentes a la ciencia y a la técnica pudieran superar las fuerzas de muerte y esclavitud." (op. cit. p. 38).

Hay algo en esta última cita que recuerda a los planteamientos de Habermas (2018), en orden a señalar que no es la modernidad ni su proyecto la que está perdida (Habermas no cree en la pretendida posmodernidad, señala que sólo estamos pagando los costos generados por la modernidad), sino que sería la racionalidad instrumental (a la que se ha orientado la modernidad en este último período), la que no permite la realización del proyecto original de la modernidad. Sintéticamente lo que propone este último autor es que la humanidad se puede salvar despojando a la modernidad de su racionalidad puramente instrumental, orientándola hacia una sociedad capaz de comunicarse desde una ética universal (claramente aparecen acá los resabios kantianos de Habermas, quien ha sido reconocido como un neokantiano).

Volviendo con Morin, este devela una contradicción. Señala que si bien es cierto por un lado el mundo se vuelve uno, por otro se divide. Sostiene que efectivamente avanzamos hacia una homogenización civilizacional, la cual se hace cada vez más presente en la uniformización mundial (en términos económicos, políticos, de integración, cultural, en la moda, y en una variedad amplia de otros aspectos), no obstante, lo cual surgen por todo el orbe movimientos que recurren a la identidad ancestral en tanto que reacción a la globalización.

Se puede hacer aquí un interesante paralelo con otro libro francés contemporáneo del texto que analizamos en este estudio, hablamos de "¿Podremos Vivir Juntos? Iguales y Diferentes" (1997) de Alain Touraine. En este, el autor da cuenta del proceso globalizador (el que en aquel entonces no mostraba la profundización que exhibe 23 años después) por el cual el mundo está transitando. Señala que en esta vorágine de "mundialización", efectivamente hay quienes se plegan muy cómodos al proceso, en tanto que otros no... es ahí donde surge la afirmación de las identidades culturales locales, proceso que Touraine denomina "recomunitarización", es decir, la vuelta a la comunidad ${ }^{19}$.

Morin pone en tela de juicio la pretendida benignidad del desarrollo "El desarrollo mismo ha creado más problemas de los que ha resuelto y ha conducido a la crisis profunda de civilización que afecta a las sociedades prósperas de occidente" (op. cit. p. 35). Esta idea tiene como principal responsable a la orientación que se le ha dado al desarrollo, concibiéndolo desde una perspectiva técnico-económica. 
Junto con el desarrollo, la crítica de este autor también cae sobre la racionalización, pues está a diferencia de la racionalidad, sólo se ocupa del cálculo, de lo cuantitativo, ignorando que detrás de todas esas cifras y datos hay personas, individuos de carne y hueso con sufrimientos reales y necesidades reales ${ }^{20}$.

La mirada de Morin no es tan negativa como la de la primera generación de la Escuela de Frankfurt. Él ve posibilidades de avanzar hacia un mundo mejor partiendo, como se ha repetido a lo largo de este estudio, de la posibilidad de emergencia y consolidación del paradigma de la complejidad, otra alternativa está dada por la profundización de las contracorrientes descritas anteriormente. Incluye en este abanico de elementos de cambio a las "inacabables fuentes de amor humano." 21

"La posibilidad antropológica, sociológica, cultural, mental de progreso, restaura el principio de esperanza sin certeza 'científica' ni promesa 'histórica'” (op. cit. p. 39). Para todo ello se requiere una reforma del pensamiento. Necesitamos una conciencia planetaria, conciencia primero que todo, de que habitamos el mismo planeta. "Todos los humanos, desde el siglo XX viven los mismos problemas fundamentales de la vida y la muerte." (op. cit. p. 40).

El llamado de este autor es a que retomemos nuestra conciencia antropológica, ecológica, civil terrenal, espiritual, ya no es necesario dirá, oponer lo universal a lo particular. La idea es integrar lo local en lo global con conciencia de identidad propia, aportando desde nuestra cultura de origen, "la era de la fecundidad de los Estados nación dotados de un poder absoluto está ravaluada, lo que significa que es necesario, no desintegrarlos, sino respetarlos integrándolos en conjuntos y haciéndoles respetar el conjunto del cual hacen parte." (op. cit.). Aparece acá una exhortación hacia asumirse desde una poli-identidad.

\section{5.- Enfrentar las incertidumbres}

La idea central de este capítulo dice relación con el contexto de incertidumbre en el cual nos deberemos mover en el siglo XXI, partiendo por la comprensión de la incertidumbre en la historia humana, aspecto que va íntimamente ligado a la impredecibilidad. Al respecto se debe señalar que los sistemas (el sistema planetario entre ellos) se conducen en cuanto a sus procesos de una manera no lineal, es decir, dentro de ciertos márgenes razonables, funcionan con un nivel de impredecibilidad. Montbrun plantea que "los sistemas caóticos son sistemas complejos que se conducen de manera extraña e impredecible." (Montbrun, A. 2005 p. 2).

"Una gran conquista de la inteligencia sería poder, al fin, deshacerse de la ilusión de predecir el destino humano." (Morin, E. 1999 p. 42), ilusión que claramente aparece como un resabio del positivismo más clásico y la idea de encontrar las leyes que regían la naturaleza. Morin liga todo esto a la idea de progreso indefinido que se instala conforme se desarrolla y consolida el paradigma moderno. En palabras de este autor, estaríamos asistiendo al "derrumbamiento del mito del Progreso." (op. cit.), esto es, se puede progresar, pero sobre eso también pesa una fuerte carga de impredecibilidad.

En esta misma lógica el texto muestra una serie de eventos históricos que antes de su ocurrencia no estaban en los presupuestos de nadie. Menciona por ejemplo la impredecibilidad 
de que, tras el atentado de Sarajevo de 1914, se desarrollara una guerra mundial, o que el tratado de Versalles que pone fin a la primera guerra engendraría la segunda. Por medio de estos y otros ejemplos, el autor va mostrando la imposibilidad de predecir en el mundo de la complejidad, en un planeta complexus.

Continuando con el texto, este entrega algunas características de la historia. Ya hemos visto que no es lineal, y que, por el contrario, como señala Alberto Montbrun, es compleja e impredecible (Montbrun, 2005), a ello Morin agrega el hecho de que es creadora y destructiva, produciéndose aquí la dialéctica que permite el devenir humano. "No existen solamente las innovaciones y las creaciones. También existen las destrucciones. Estas pueden traer nuevos desarrollos: así como los desarrollos de la técnica, la industria y el capitalismo han arrastrado la destrucción de las civilizaciones tradicionales." (op. cit. p. 44).

Con todo ello el autor va afianzando su idea de que la historia no es lineal, no tiene una evolución recta, sino por el contrario está llena de aspectos impredecibles, paradójicos, contradictorios, etc. Sobre el tema de la linealidad, cabe mencionar a una de las primeras teorías en la Antropología, a saber, el evolucionismo unilineal, cuyo representante más destacado es Lewis Henry Morgan, a quien se le atribuye nada más ni nada menos que el honor de ser uno de los creadores de la etnografía (1851) en tanto que método de análisis de la cultura. Morgan va a adherir a teoría denominada evolucionismo unilineal, concepción que pretendía que todos los grupos humanos transitaban siempre y en todo tiempo y espacio, por las mismas fases históricas. En particular señalaba que las sociedades humanas transitaban por tres estadios: salvajismo barbarie - civilización. Edward Tylor, antropólogo contemporáneo de Morgan y a quien se le atribuye el haber creado el concepto moderno de Cultura, así como la idea de que esta es susceptible de ser estudiada científicamente, también creía férreamente en el evolucionismo unilineal, pero su evolucionismo estaba más bien orientado al plano religioso, donde planteaba que se iba siempre (todas las culturas y sociedades humanas) desde el animismo al monoteísmo, y desde este al positivismo (Kottak. 2004). La semejanza con los estadios evolutivos de Comte no es casual, cronológica y geográficamente estaban muy cerca.

Hoy el evolucionismo unilineal y el evolucionismo en general en las ciencias sociales está ampliamente superado y hay teorías que explican los mismos fenómenos de una manera más completa.

Profundizando en el tema de las incertidumbres Morin señala que "Hay que aprender a enfrentar la incertidumbre puesto que vivimos una época cambiante donde los valores son ambivalentes, donde todo está ligado. Es por eso que la Educación del futuro debe volver sobre las incertidumbres ligadas al conocimiento." (op. cit. supra p. 45).

El paradigma de la complejidad nos previene sobre algunos aspectos vinculados a la teoría de sistemas, más precisamente al funcionamiento de los sistemas sociales, los cuales poseen una característica que Montbrun (2005) denomina coevolución, lo que, sintéticamente plantea la idea de una transformación recíproca resultante de la relación sistema/entorno (relación que por lo demás el autor refiere como co-construida por el observador). Esta idea de coevolución es el resultado lógico si se piensa que los sistemas no se producen, surgen o generan en el vacío, sino 
en un trasfondo más amplio y complejo llamado "entorno". El entorno continuamente promueve cambios en el sistema. Parte del trabajo del sistema es tener subsistemas de retroalimentación y acoplamiento que le permitan adaptarse a los cambios que el entorno propulsa. Si bien es cierto, el entorno genera cambios en el sistema, este último también produce cambios en el entorno, ya que es una relación recíproca, asimétrica, pero recíproca (Montbrun 2005).

La educación y principalmente la pedagogía del siglo XXI deben necesariamente considerar la relación sistema/entorno, pues esta es clave para comprender la complejidad asociada a cada fenómeno social.

A ello se debe agregar el principio de incertidumbre planteado por Morin:

- Incertidumbre cerebro-mental

- Incertidumbre lógica

- Incertidumbre racional

- Incertidumbre sicológica

La primera derivada del hecho analizado en páginas precedentes de que la traducción que realiza la mente de la realidad no es una copia fiel, sino más bien un acople mediado por el lenguaje (caracterizado por la diada nóumeno/fenómeno). La segunda es una crítica al sistema de análisis lógico aristotélico (ni la contradicción es señal de falsedad ni la no contradicción es señal de verdad). La tercera fue analizada cuando planteamos la idea de que la racionalidad corre el riesgo de transformarse en racionalización, con lo que se cae en fría y "neutra" cuantificación. La última, la incertidumbre sicológica ${ }^{22}$ introduce un elemento freudiano al señalar que no somos nunca totalmente conscientes de lo que pasa en nuestra mente, pues esta "siempre conserva algo fundamentalmente inconsciente." 23 (Morin, E. 1999 p. 45).

Siempre en el plano de la incerteza, y retomado la incertidumbre cerebro-mental, el texto plantea que "Las ideas y teorías no reflejan, sino que traducen la realidad, la cual pueden traducir de manera errónea. Nuestra realidad no es otra que nuestra idea de la realidad." (op. cit.). El socioconstruccionismo ${ }^{24}$ plantea algo muy similar, en términos de visualizar a los fenómenos sociales desde una perspectiva contextual, esto es, dentro de este campo teórico, una determinada práctica social compartida y validada por un grupo determinado puede parecer algo totalmente natural a sus ojos, pero en realidad esto es sólo parte de ese sistema cultural en particular y no un hecho universal (por ejemplo, la ablación en ciertas tribus africanas es una práctica totalmente aceptada y reproducida culturalmente). Podría alguien argumentar frente al ejemplo de África el tema del relativismo cultural, pero no puede perderse de vista el hecho de que, el relativismo se acaba cuando estamos frente a hechos que afectan derechos humanos $u$ otros aspectos donde se ha llegado a consensos relacionados con su protección. La invitación que nos hace Morin en este sentido es a interpretar contextualmente la realidad antes que buscar el realismo propiamente tal.

Dentro de la batería argumental moriniana, aparece un concepto clave al momento de poder sortear con éxito el riesgo de caer en la ilusión, el error y la incertidumbre, hablamos de la "oportunidad para llegar a un conocimiento pertinente ${ }^{25}$, el cual necesita exámenes, verificaciones y convergencia de indicios" (op. cit. p. 46). 
Esto implica la búsqueda de concordancias a partir de una "verificación de conjunto que confirma la legitimidad" (op cit.). Subyace a todo esto la búsqueda de certezas en un intrincado laberinto de incertidumbres. La Educación y la pedagogía del siglo XXI deben enseñar a navegar en aguas turbulentas, impredecibles, interdependientes, capaces de autoorganización, autopoiéticas, donde la posibilidad de generar un efecto mariposa ${ }^{26}$ es una realidad siempre plausible.

Nuestro autor plantea también la relación entre las incertidumbres y la ecología de la acción, para señalar que toda acción y/o elección en este mundo de la complejidad conlleva riesgos, los cuales implican que, una vez emprendida una acción, esta empieza a escaparse de control (recordar el principio de no linealidad planteado antes). Por ello es necesario realizar el seguimiento de nuestras acciones/elecciones con la finalidad de cautelar el curso de las mismas, para reorientarlas, reorganizarlas o de ser necesario, "destruirlas".

"La ecología de la acción es, en suma, tener en cuenta su propia complejidad, es decir riesgo, azar, iniciativa, decisión, inesperado, imprevisto, conciencia de desviaciones y transformaciones." (op. cit.).

La ecología de la acción implica algunos principios:

- El bucle riesgo-precaución: implica poder ligar ambos conceptos a pesar de la oposición que ambos comportan. Tratar de tomar riesgos controlados.

- El bucle fines-medios: dada la no linealidad de este paradigma, es posible que no siempre haya una conexión uno es a uno entre los fines y los medios planteados. Se hace necesaria la más acuciosa examinación de la situación antes de proceder.

- El bucle acción-contexto: la acción lleva incorporada en si la posibilidad de fracaso, pero también la de corrupción del sentido primigenio de lo planificado. La recomendación acá es proceder con la máxima cautela de las consecuencias.

Morin nos previene de la dificultad de calcular los efectos de una determinada acción a largo plazo, lo que no ocurre necesariamente con las acciones a corto plazo, las que por su naturaleza podrían tener un grado mayor de control del ejecutante. La ecología de la acción no propone inacción, sino actuar reconociendo y sopesando los posibles riesgos y tener siempre una estrategia que permita reorganizar la acción, cuando no anularla definitivamente (arriesgarse con una estrategia previa). Junto con este llamado a la estrategia, Morin nos invita a tener plena conciencia de la apuesta que implica nuestra decisión, y a no dudar en sobreponer la estrategia al programa, entendiendo a este como la prescripción de pasos a seguir. En palabras más sencillas, si las condiciones de contexto cambian (algo totalmente plausible desde la mirada de la complejidad), no se debe dudar en poner en marcha las acciones remediales que la estrategia contiene, pues esta ya tiene considerada la incertidumbre, las probabilidades y las improbabilidades (Morin. 1999).

"Se puede y se debe luchar contra las incertidumbres de la acción, se puede incluso superarlas a corto o mediano plazo, pero nadie pretendería eliminarlas a largo plazo." (op. cit. p. 49). Las oportunidades conllevan riesgos, nuestro raciocinio debe saber diferenciar ambos. Debemos "entonces, confiar en lo inesperado y trabajar para lo improbable." (op. cit.). 


\section{6.- Enseñanza de la comprensión}

El tema de la comprensión en el ámbito del conocimiento no es nuevo ni se crea con el paradigma de la complejidad o la teoría de sistemas. Sus antecedentes son más profundos aún, hallándose antecedentes directos en Weber y su concepción de lo que debe ser la sociología: "Debe entenderse por sociología una ciencia que pretende comprender, interpretándola, la acción social, para de esa manera explicarla causalmente en su desarrollo y efectos" (Weber, M. 2002 p. 5).

Podríamos no obstante remontarnos más atrás en la historia, indagando en los cimientos de las teorías de la interpretación o de la hermenéutica, donde encontraríamos a una serie de autores, principalmente alemanes, filósofos e historiadores tales como Kant, Hegel, Droysen, Dilthey, entre muchos otros que fueron allanando el camino para que, a finales del siglo XIX Weber comenzara a dar vida a su sociología de la comprensión, pero ese no es el objetivo de este texto, sino situar los planteamientos de Morin acerca de la educación y la pedagogía del siglo XXI incorporando elementos del paradigma de la complejidad.

Antes de continuar, y sólo para clarificar esto, se debe señalar que la visión weberiana surge también como una respuesta al curso que habían tomado las ciencias sociales y en particular la sociología a fines del siglo XIX con la otra gran figura de esta disciplina de esos primeros años, Emile Durkheim.

Este último, se dio a la gran labor de separar a la sociología de otras ramas del conocimiento que reclamaban como suyo el campo de acción de la sociología (la filosofía y la psicología). Esto en gran parte lo consigue delineando esta nueva ciencia/disciplina desde el positivismo (estadísticas, formulación de leyes, trabajo empírico, etc.), y dando vida a uno de los estudios más célebres y recordados: El Suicidio (1897).

De ahí en más, la sociología se orientará fuertemente hacia el positivismo, esto hasta que comiencen a posicionarse en el mundo intelectual de la época los planteamientos de Weber, quien va a señalar que el "objeto" de estudio de las ciencias sociales es bastante diferente del de las ciencias naturales. En primer lugar, este "objeto" no es una cosa, (aun cuando Durkheim en Las Reglas del Método Sociológico, 1895, llama a tomar los hechos sociales como cosas -cosificar) pues es alguien que piensa, que siente, que ríe y llora... es un ser humano tal cual lo es el investigador social (con esto, al menos en la sociología, se diluye la relación sujeto-objeto).

Todo esto llevará a Weber a plantear que el positivismo si bien ha contribuido enormemente al desarrollo del conocimiento, no es la forma más idónea de estudiar en el ámbito de las ciencias sociales y en particular de la sociología. Ante ello, va a proponer la idea de que la "acción social" (su gran eje de análisis) debe entenderse como toda acción que el ser humano realiza desde la inteligibilidad, desde el empleo de la razón, por ello, más que ser captada matemática y estadísticamente, la orientación debe ser hacia el comprender, entender (verstehen) e interpretar el sentido subjetivo que el actor social imprime a su accionar. 
Nace así el cualitativismo "El enfoque cualitativo tiene su origen en otro pionero de las ciencias sociales, Max Weber (1864-1920), quien introduce el término "wersteben" o "entendimiento", reconociendo que además de la descripción y la medición de variables sociales deben considerarse los significados subjetivos y el entendimiento del contexto donde ocurre el fenómeno" (Hernández, R. Fernández, C. Baptista, P. 2003 p. 4).

Volviendo a Morin, el capítulo inicia mostrando la magnitud de la interdependencia en el planeta hoy en día, y cómo esta se ve reforzada por la tecnología, por redes tales como la internet o la comunicación celular. Ante todo ello, el autor se detiene a pensar en el tema de la comunicación, y cómo, casi como una paradoja, mientras más instancias de comunicación hay, la incomprensión sigue estando presente en la humanidad...

Señala posteriormente que los medios de comunicación son simplemente eso, "medios", y su empleo o uso no garantiza per se el entendimiento o la comprensión entre las personas. Por otro lado, el texto hace explícita la necesidad imperiosa de mayor comunicación en la humanidad, endilgándole esta responsabilidad a la educación y por extensión a la pedagogía, pretendiendo de esta forma que en este educar para la comprensión, "se encuentra justamente la misión espiritual de la educación: enseñar la comprensión entre las personas como condición y garantía de la solidaridad intelectual y moral de la humanidad." (Morin, E. 1999 p. 50). En el fondo lo que plantea el autor es que la educación y la pedagogía del nuevo siglo deben enseñar en la solidaridad y la moral humana.

Siguiendo el texto, se plantea la existencia de dos tipos de comprensión, una de corte intelectual: objetiva, y otra de tipo humana: intersubjetiva ${ }^{27}$. La explicación por su parte tiene que ver con conocer un objeto aplicando modos objetivos de conocimiento (como el método científico, por ejemplo), elemento consustancial a la comprensión objetiva o intelectual. Pero la comprensión humana requiere un elemento adicional: el conocimiento de sujeto a sujeto, esto es, por medio de la empatía, del ponerse en los zapatos del otro por medio de la cordialidad, la generosidad, "Las demás personas se perciben no solo objetivamente, sino como otro sujeto con el cual uno se identifica y que uno identifica." 28 (op. cit. p. 51). Este tipo de entendimiento, más que producirse en el plano objetivo, se establece en un conjunto de elementos comunes $y$ significados compartidos denominado intersubjetividad.

Ambas formas de comprensión tienen una serie de obstáculos externos, entre ellos podemos contar al ruido que crea mal entendidos; a la polisemia de una noción, lo que puede contribuir a la confusión; a la ignorancia propia de la cultura del otro, lo que provoca o puede provocar un mal juzgamiento; a la incomprensión de los valores de la alteridad (muy relacionado con el anterior escollo); a la incomprensión de la ética de otra cultura, entre otros varios obstáculos.

También encontraremos obstáculos internos a la comprensión tales como el etnocentrismo, entendido básicamente como la propensión de personas, culturas o sociedades a percibir que sus propias formas culturales son superiores a las demás (sus comidas, sus dioses, su democracia, su sistema económico, su color de piel, etc.). El egocentrismo, que implica también 
ver en la alteridad un lugar de peligro, lo malo, lo negativo, es la incomprensión de uno mismo proyectada en el otro. Acá el llamado a la educación y la pedagogía del nuevo siglo es a formar en el relativismo cultural, entendiendo que todas las culturas son relativas a sí mismas, y no se debe interpretar o juzgar una cultura con los parámetros propios.

Otro de los elementos que juegan en contra de la comprensión es lo que Morin denomina el espíritu reductor, o propensión a creer que a través de una parte se conoce el todo, que por medio de un componente se conoce el sistema completo. El texto nos previene de esto, instándonos a no reducir la totalidad a una parte, sugerencia que también extiende al fanatismo de las ideas al punto de transformarlas en un dogma, señalando que esto clausura el entendimiento más que aperturarlo.

Pero, así como Morin nos previene sobre los obstáculos, también nos sugiere aquellos aspectos que facilitan, permiten y amplían la comprensión, planteando la vía de lo intelectual, lo moral, lo ético, etc.

Sobre este último punto, se plantea a la ética de la comprensión como el comprender desinteresadamente, sin esperar retribución por ello, comprender incluso a quien quiere dañarnos y se niega a comprendernos, nos ayuda a entender el fanatismo humano. Es un comprender humanizante, a través del cual podemos entender que todos nos hemos equivocado alguna vez. Una ética tal nos lleva finalmente a la compresión de nosotros mismos.

La introspección, entendida como autoexamen continuo de sí mismo es otro de los elementos que contribuyen a la comprensión. La idea de fondo es que, por la vía del autoconocimiento de nuestras falencias, podemos comprender también al resto. Por usar un concepto vertido en las páginas precedentes, la introspección nos permite realizar nuestra propia retroalimentación.

El comprender al resto, implica necesariamente el entender la complejidad humana, tomar conciencia plena de ello. Este mismo entender la alteridad implica el desarrollo de la tolerancia, la que, tal cual lo propone el texto, va más allá de la simple aceptación de aquello que nos contraría, implica incluso una voluntad de sufrir internamente antes que abandonar tal tolerancia.

El texto también promueve una ética y cultura planetaria, incluyendo en este concepto la idea de solidaridad moral entre los seres humanos. No será sino accionando desde el relativismo cultural, que podremos avanzar hacia el conocimiento del otro, de las culturas diferentes, intentado descubrir lo positivo en el otro más que lo negativo. Subyace acá la idea de cooperación entre las culturas más que los antagonismos. Poder entender que el desarrollo humano en todas sus áreas más ha tenido que ver con el préstamo y la reciprocidad que con el aniquilamiento del otro. Este último punto parece incluso evidenciarse más allá del horizonte de nuestra especie, y comprender que no ha sido la selección de las especies la que ha permitido la proliferación de la vida en el planeta, sino la cooperación. Desde este punto de vista, la comprensión de las diferentes culturas no puede sino traer beneficios a todos. En el entendimiento mutuo puede 
surgir la comprensión cabal de que somos habitantes de la misma casa, y que el cuidado de esta es deber de todos. Sólo así parece posible salvar, perfeccionar y proyectar los ideales democráticos que occidente ha intentado (o ha declarado intentar) expandir por el mundo.

"La comprensión es a la vez medio y fin de la comunicación humana. El planeta necesita comprensiones mutuas en todos los sentidos. Dada la importancia de la educación en la comprensión a todos los niveles educativos y en todas las edades, el desarrollo de la comprensión necesita una reforma planetaria de las mentalidades, esa debe ser la labor de la educación del futuro." (op. cit. p. 57).

\section{7.- La ética del género humano}

Entre las múltiples ideas que Morin (1999) desarrolla en este texto, está aquella que señala que la complejidad de lo humano se devela en la triada: individuo - sociedad - especie. Esta se manifiesta en una dinámica dialéctica en la cual cada uno de sus componentes retroactúa sistémicamente, de manera sinérgica, afectándose mutuamente, produciéndose y autoproduciéndose autopoiéticamente. Como producto de esto emerge la cultura. Sobre esta última el autor señala: "La cultura está constituida por el conjunto de hábitos, costumbres, prácticas, saber-hacer, saberes, reglas, normas, prohibiciones, estrategias, creencias, ideas, valores, mitos, que se perpetúan de generación en generación, se reproduce en cada individuo, genera y regenera la complejidad social". (Morin, E. 2003 p. 40). En todo este entramado de complejidad surge la conciencia, en palabras de Morin, nuestro espíritu propiamente humano.

A partir de todo esto se instala una ética diferente, una antro-poética que debe incluir en sus planteamientos y consideraciones a la triada completa.

Esta antro-poética nos invita a asumir la triada como parte de la complejidad del siglo XXI, avanzar hacia la humanidad que hay en cada uno de nosotros, humanizar a la humanidad, guiar la vida, tender a la unidad por medio de la diversidad, respetar la identidad de la alteridad, ser solidarios, vivir acorde a la ética de la comprensión e instruir en una ética del género humano (Morin. 1999).

Este autor enfoca el análisis en el binomio individuo - sociedad, a partir de lo cual reintroduce la enseñanza de la democracia. Vuelve a mostrar cómo ambos conceptos se afectan mutuamente, enfatizando la idea de que la democracia es una co-construcción en la que estamos todos involucrados y que funciona básicamente por medio de las libertades individuales y la responsabilidad que le cabe a cada uno en su mantención y reforzamiento.

\section{DISCUSIÓN}

Profundizando más en el tema de la democracia, el texto desarrolla una mirada complejosistémica acerca de qué es la democracia. Explica por ejemplo que la soberanía popular está limitada por la obediencia a la justicia y que al mismo tiempo que se delega poder a quienes elegimos por medio del sufragio, a su vez estos están limitados por la división de los poderes. 
Explica también que todo esto se supedita al deber del Estado de protección de la vida privada de los ciudadanos. Plantea igualmente que todo este complejo andamiaje sería imposible sin la existencia del consenso ciudadano, introduciendo así la idea de las mayorías.

No obstante, enfatiza el hecho de que aun cuando la democracia se nutre del consenso, esta necesita de la diversidad y los antagonismos "El respeto de la diversidad significa que la democracia no se puede identificar con la dictadura de la mayoría sobre las minorías; ella debe incluir el derecho de las minorías y contestatarios a la existencia y a la expresión y debe permitir la expresión de ideas heréticas y marginadas." (op. cit. p. 59). La democracia debe proteger la diversidad y sus ideas, cuidando de igual manera la pluralidad de los medios de información. ${ }^{29}$

Hay acá una crítica del autor a los regímenes autoritarios y a cómo en ellos las libertades van siendo restringidas, socavando de paso las bases de la democracia. El debate de ideas contrapuestas aparece como un elemento catalizador y fortalecedor de la vida democrática, cuyo sustento son los ideales de liberté, égalité et fraternité.

Inscribe también a la democracia dentro de los sistemas complejos, dado que los elementos que los componen (los que a su vez actúan como subsistemas) poseen características de pluralidad, competencia y antagonismo, es un sistema que no existe sin diversidad ni pluralidad, esta le es concomitante como ya se ha señalado.

Otra de las características que se destacan de la democracia en este análisis es su carácter predominantemente dialógico, esto es, en su esencia incluye la diada conflicto/consenso, es decir, requiere necesidad de negociación entre ideas opuestas, diálogo.

El texto también realiza una diagnosis de la democracia en el mundo, señalando que esta se encuentra en construcción, no siendo un hecho social ${ }^{30}$ acabado. Por lo demás, es una estructura social continuamente amenazada por los totalitarismos que aún perviven en el mundo. Respecto de su perfeccionamiento pone como ejemplo la igualdad que las mujeres han ido logrando paulatinamente. Critica al socialismo occidental su escasa democratización en el ámbito económico social, a la empresa privada por su excesiva jerarquía autoritaria y su escasa promoción del ámbito sindical. Morin se detiene en la idea de incapacidades democráticas: "Hay procesos de regresión democrática que tienden a marginar a los ciudadanos de las grandes decisiones políticas (bajo el pretexto de que estas son "muy complicadas" y deben ser tomadas por "expertos" tecnócratas)." (op. cit. p. 61). Esta última idea ha sido desarrollada por Norberto Bobbio en su texto El Futuro de la Democracia (1986), donde plantea la existencia de "sistemas expertos" que tienden a alejar a los profanos de participar en sistemas demasiado complejos. Bobbio critica precisamente que la democracia (el gobierno del pueblo) hoy esté cada vez más alejada de la ciudadanía, cooptada por tecnócratas que elevan las decisiones democráticas a esferas inalcanzables por el ciudadano común y silvestre. Muy en sintonía con este autor italiano, Morin lanza la idea de una democracia y una política que se ha ido paulatinamente despolitizando, y que tienden a diluirse en una administración burocrática, tecnócrata, cuantitativa, entiéndase la híper especialización, la división, la fragmentación, la parcelación. "Entre más técnica se vuelve la política, más retrocede la competencia democrática" (op. cit.). 


\section{REFLEXIONES FINALES}

Morin ve emerger un conflicto latente entre aquellos que entenderán el juego democrático versus aquellos que quedan marginados por no comprender este sistema experto (Bobbio 1986). De seguir este camino se asistirá a un debilitamiento paulatino del civismo a manos de la tecno-burocracia aliada al poder económico, generando atomización social y desidia respecto de temas socio democráticos que a todos incumben. ${ }^{31}$

El texto finaliza haciendo un llamado a la antropo-ética, la cual por más intentos de acallarla que se han realizado, sigue viva en una serie de campos del saber tales como las religiones universalistas, en el humanismo, en el respeto a los DD.HH., o en el imperativo categórico kantiano (de corte universal), entre otros.

Es la amenaza de muerte global la que hoy nos obliga a replantearnos nuestra relación con el otro, con la especie, con la humanidad, con la ecología, la diversidad, la oposición, la divergencia, pues de otra manera este planeta que nos pertenece a todos y del cual todos somos habitantes, esta especie de la cual todos formamos parte, corre riesgos y peligros que podrían arrastrar tras de sí a la vida misma en la tierra bajo amenaza de autodestrucción, "la expansión y la libre expresión de los individuos constituyen nuestro propósito ético y político para el planeta; ello supone a la vez el desarrollo de la relación individuo - sociedad en el sentido democrático, y el desarrollo de la relación individuo especie en el sentido de la Humanidad; es decir, que los individuos permanecen integrados en el desarrollo mutuo de los términos de la triada individuo - sociedad - especie. No tenemos las llaves que abran las puertas de un futuro mejor. No conocemos un camino trazado "el camino se hace al andar" (Antonio Machado). Pero podemos emprender nuestras finalidades: la continuación de la hominización en humanización, vía ascenso a la ciudadanía terrestre. Para una comunidad planetaria organizada: ¿no sería esa la misión de una verdadera Organización de las Naciones Unidas? (op. cit. p. 64).

\section{Notas:}

${ }^{1}$ Se plantea más adelante en el texto una diferenciación entre Educación y Pedagogía que se estima pertinente para clarificar aún más este trabajo.

${ }^{2}$ A la base de esta distinción está la idea de que la pedagogía es una especie de brazo operativo de la educación.

${ }^{3}$ Para una mayor profundización sobre este tema, consúltese el texto de Patricio Meller del año 2018 “Claves Para Entender la Educación del Futuro. Creatividad y Pensamiento Crítico”

${ }^{4}$ Ambos fueron estudiantes de Niklas Luhmann en la Universidad de Bielefeld, Alemania.

${ }^{5}$ Para mayor conocimiento sobre el concepto de Cibernética véase Meza y Macker: Cibernética y Comunicación en el Plano Local, en Revista de Educación Contextos $\mathrm{N}^{\circ} 1$ y $\mathrm{N}^{\circ} 2$ Municipalidad de Recoleta. https://www.recoleta.cl/wp-content/uploads/2019/08/Contextos-N\%C2\%BA-1.pdf

${ }^{6}$ Discrepancias que ya estaban presentes en el siglo XVII con autores de la talla de Locke, Kant o Hume, sobre todo en temáticas tales como la diferenciación entre nóumeno y fenómeno.

${ }^{7}$ Para mayor profundización sobre este tema, desde la mirada de la neuropsicuiatría, consúltese la obra de Jorge Barudy. 
${ }^{8}$ Niklas Luhmann plantea la idea las paradojas en los sistemas, una de ellas por ejemplo es que más complejidad genera menos complejidad (2007).

9 No deja de llamar la atención que, desde otra perspectiva teórica y otra tradición de pensamiento, Jurgen Habermas plantee la crítica a la racionalidad instrumental (2018), en tanto que gran escollo para alcanzar y completar el proyecto modernizador que emprende el mundo al abrazar el nuevo paradigma de la modernidad.

10 Por ejemplo, hasta fines del medioevo y ya entrada la modernidad, se seguía creyendo en el sistema geocéntrico, aun cuando desde la Grecia Clásica con Ptolomeo y autores medievales como Copérnico, se especulaba lo contrario.

${ }_{11}$ Para mayor conocimiento sobre los paradigmas y su mecánica de cambio, léase La Estructura de Las Revoluciones Científicas, de Thomas S. Khun, de 1962 y reeditado varias veces.

${ }^{12}$ Hay un alto grado de coincidencia entre estos planteamientos y lo señalado por el profesor José Maza en su libro "Somos Polvo de Estrellas" (2017), donde señala no de forma metafórica, sino concreta, que en cada uno de nosotros existen partículas y una serie de componentes que fueron formados en alguna estrella en el cosmos.

${ }^{13}$ Hay una similitud acá con los planteamientos de George Mead en su texto de 1934 Mind Self and Society.

${ }^{14}$ Como ejemplo basta pensar en el gran éxito y penetración de la gastronomía peruana en nuestro país.

${ }^{15}$ En la década de los 50', superando lo estático del estructural funcionalismo (el paradigma de la época para parte de las CCSS sociales), la antropología simbólica con autores como Víctor Turner va a incursionar fuertemente en esta mirada. Famosa es su etnografía en África, en la tribu de los Ndembu titulada "La Selva de los Símbolos".

${ }^{16}$ He aquí uno de los elementos centrales de la teoría de sistemas desarrollado desde Bertalanffy hasta Morin, pasando por Luhmann, Montbrun y otros, la retroalimentación, o capacidad de los sistemas (abiertos) de autoobservarse, hallar entropía y corregir el rumbo.

${ }^{17}$ Esta idea Luhmann la desarrolla en Teoría Política en el Estado de Bienestar (1997) y usa como ejemplo el hecho de que el sistema político constantemente está colapsado precisamente porque intenta ordenar a otros subsistemas del sistema social, pero como cada uno funciona como caja negra (black box), y tiene su propia autoobservación y autopoiesis, mal puede el sistema político orientar lo que hay dentro de la black box, pues no sabe a ciencia cierta qué hay dentro de este. 18 John Durston, Antropólogo Social, quien ha realizado numerosos trabajos para la CEPAL, profundiza la idea de Capital Social, señalando que este es el resultado de un tipo particular de relación social basado en la confianza, la cooperación, la reciprocidad y la solidaridad. Este tipo de relaciones traería aparejado mayores beneficios para aquellos que la utilizan, que para quienes no lo hacen.

${ }^{19}$ El texto de Touraine tiene un correlato en nuestro país, nos referimos al texto "La sociedad en que vivi (re) mos, introducción sociológica al cambio de siglo", de Manuel Antonio Garretón (2000).

20 Hay acá marcadas similitudes con la crítica de la Escuela de Frankfurt iniciada en los años 30' en cuanto a concebir a la modernidad como un paradigma cooptado por la racionalidad instrumental (Habermas plantea lo mismo). En tal sentido, no fue casual que los primeros textos de Adorno, Horkheimer o Marcuse hayan tenido como blanco de ataque a la modernidad y su 
racionalidad instrumental, a la modernidad y a las promesas no cumplidas (sintetizadas en la consigna libertad, igualdad, fraternidad).

${ }^{21}$ Imposible no ver aquí una similitud con la Biología del Amor, de Humberto Maturana.

22 Morin omite la " $p$ ".

${ }^{23}$ Esta es en cierta medida también la opinión de Foucault en Nietzsche, Freud y Marx (1967), donde este autor plantea la idea de que la modernidad occidental tiene tres grandes heridas causadas por estos autores, una de ellas es precisamente la idea de que el paradigma de la razón está gobernado por el inconsciente más que por el consciente.

${ }^{24}$ Para mayor información al respecto, consúltese la obra de Kenneth J, Gergen.

25 El negreado es mío.

${ }^{26}$ Alberto Montbrun (2005) señala que en el paradigma de la complejidad siempre es posible que, dada la impredecibilidad en el comportamiento de una problemática determinada, se puedan provocar efectos que escapen completamente a lo pronosticado, esperado, proyectado, con inusitadas consecuencias.

27 La comunicación humana en el sistema teórico de la sociología fenomenológica de Schutz, Berger y Luckmann pasa precisamente por la serie de significados y sentidos compartidos por un grupo humano en la intersubjetividad. Para mayor conocimiento al respecto, véase La Construcción Social de la Realidad (1964).

28 George Mead en los inicios del interaccionismo simbólico encuentra un principio similar al descrito por Morin, Ilama a esto "el otro generalizado". Mind, Self and Society (1934)

${ }^{29}$ Sobre este último punto, se podría hacer la analogía con Chile y pensar qué tanto protege el Estado chileno la pluralidad de los medios de comunicación. Para nadie es una sorpresa que los canales de televisión tienen líneas editoriales altamente cooptadas por ideas neoliberales, o que el avisaje en la prensa escrita (el gran sustento de periódicos y diarios) se entrega básicamente a los dos grandes consorcios del país (Copesa y El Mercurio), dejando sin este sustento a una gran masa de medios de prensa independientes.

30 Para mayor profundización en concepto de "hecho social", consúltese "Las Reglas del Método Sociológico". Emile Durkheim (1895), texto reeditado varias veces.

${ }^{31}$ Este texto de Morin fue publicado hace 21 años atrás, hoy a dos décadas de aquello, vemos que la democracia representativa de occidente no convoca a más del $50 \%$ de sufragantes. Para muestra podemos señalar que, en la última elección presidencial chilena, votó el $46 \%$ de los inscritos en el padrón electoral (emol.com/noticias/economía/2017/11/19/884005/menos-dela-mitad-de-los-chilenos-voto-participacion-electoral-alcanza-un-46-del-padron.html). respecto señalar que la situación no es muy diferente en Europa, Norteamérica ni en el resto del mundo. 


\section{BIBLIOGRAFÍA}

Arnold, M. y Rodríguez, D. (1999) Sociedad y Teoría de Sistemas. Santiago: Ed. Universitaria.

Bateson, G. (1988) Pasos Hacia Una Ecología de la Mente. Buenos Aires: Ed. Lohé - Lumen.

Berger, P. y Luckmann, T. (1986) La Construcción Social de la Realidad. Buenos Aires: Ed. Amorrortu.

Bobbio, N. (1986) El Futuro de la Democracia. México: Ed. Fondo de Cultura Económica.

Carbonell, J. (2015) Pedagogías del Siglo XXI. Alternativas Para la Innovación Educativa. Barcelona: Ed. Octaedro.

Castro, B. (2011) Aportes de Niklas Luhmann a la teoría de la complejidad. Polis vol. 10 (N²9). Recuperado de 283-300. $<$ https://scielo.conicyt.cl/scielo.php?script=sci_arttext\&pid=S071865682011000200013\&lng=es\&nrm=iso>. ISSN 0718-6568. http://dx.doi.org/10.4067/S0718-65682011000200013

Durkheim, E. (2003) Educación y Sociología. Madrid. Ed. Península S.A.

Durston, J. (2001) Capital Social- Parte del Problema, Parte de la Solución. Conferencia CEPAL. Documento de referencia, sólo para participantes. Pág. 1 - 46. https://www.cepal.org/prensa/noticias/comunicados/3/7903/durstonvale.pdf emol.com/noticias/economía/2017/11/19/884005/menos-de-la-mitad-de-los-chilenosvoto-participacion-electoral-alcanza-un-46-del-padron.html

Foucault, M. (1967) Nietzsche Freud y Marx. Bogotá: Ed. El Cielo Por Asalto.

Garretón, M. (2000) La Sociedad en que Vivi(re)mos. Santiago: Ed. LOM.

Habermas, J. (2018) Teoría de la Acción Comunicativa. Madrid: Ed. Trotta

Hernández, R. Fernández, C. Baptista, P. (2003) Metodología de la Investigación. México: Ed. Mc Graw Hill.

Kottak, C. (2004) Antropología Cultural. México: Ed. Mc Graw Hill.

Kuhn, T. (2013) La Estructura de las Revoluciones Científicas. México: Ed. Fondo de Cultura Económica.

Luhmann, N. (1997) Teoría Política en El Estado de Bienestar. Madrid: Ed. Alianza.

Maturana, H. (1966) La Objetividad. Santiago, Dolmen Ediciones.

Marx, K. (1973) La Ideología Alemana. Montevideo: Ed. Pueblos Unidos.

Maza, J (2017) Somos Polvo de Estrellas. Santiago. Ed. Planeta. 
Meller, P. (2018) Claves Para Entender la Educación del Futuro. Creatividad y Pensamiento Crítico. Santiago: Ed. Catalonia.

Meza, R. y Macker, A. (2018) Cibernética y Comunicación en el Plano Local. Contextos $\left(\mathrm{N}^{\circ} 1\right)$ y $\left(\mathrm{N}^{\circ}\right.$ 2) 30-34 y $34-37 . \quad$ Recuperado de https://www.recoleta.cl/wpcontent/uploads/2019/08/Contextos-N\%C2\%BA-1.pdf

Montbrun, A. (2005) Teoría de redes y Complejidad: Hacia una Nueva Síntesis en Ciencia Política. Segundas jornadas nacionales de Derecho político "Joaquín V. González. La Plata. Universidad de Cuyo. Pág. 1 - 11. Recuperado de file://C:/Users/micho/Desktop/CLASES/TEXTOS\%20VIRTUALES/complejidad_y_teoria_d e_redes._hacia_una_nueva_sintesis.pdf

Morin, E. (2003) El método, La Humanidad de la Humanidad. La identidad Humana. Madrid. Ed. Cátedra.

Morin, E. (1999) Los Siete Saberes Necesarios Para la Educación del Futuro. Paris: Ed. UNESCO.

Touraine, Alain. (1997) ¿Podremos Vivir Juntos? Iguales y Diferentes. México: Ed. Fondo de Cultura Económico.

Von Bertalanffy. (2006) Teoría General de los Sistemas. México: Ed. Fondo de Cultura Económica. Weber, Max. (2002) Economía y Sociedad. Madrid: Ed. Fondo de Cultura Económica.

Wiener, Norbert. (1988) Cibernética y Sociedad. Buenos Aires: Ed. Sud-americana. 